\section{BMJ Open \\ Respiratory \\ Research}

\title{
Aetiology of acute respiratory infection in preschool children requiring hospitalisation in Europe - results from the PED-MERMAIDS multicentre case-control study
}

Malte Kohns Vasconcelos (D) , ${ }^{1,2}$ Katherine Loens, ${ }^{3,4}$ Louise Sigfrid, ${ }^{5}$ Elias losifidis, ${ }^{6}$ Cristina Epalza, ${ }^{7}$ Daniele Donà, ${ }^{8}$ Veerle Matheeussen, ${ }^{3,4}$ Savvas Papachristou, ${ }^{6}$ Emmanuel Roilides, ${ }^{6}$ Manuel Gijon, ${ }^{7}$ Pablo Rojo, ${ }^{7}$ Chiara Minotti, ${ }^{8}$ Liviana Da Dalt, ${ }^{9}$ Samsul Islam, ${ }^{1}$ Jessica Jarvis (D) , ${ }^{1,10}$ Aggeliki Syggelou, ${ }^{11}$ Maria Tsolia, ${ }^{11}$ Maggie Nyirenda Nyang'wa, ${ }^{12}$ Sophie Keers, ${ }^{12}$ Hanna Renk, ${ }^{13}$ Anna-Lena Gemmel, ${ }^{13}$ Carmen D'Amore, ${ }^{14}$ Marta Ciofi degli Atti, ${ }^{14}$ Carmen Rodríguez-Tenreiro Sánchez, ${ }^{15,16}$ Federico Martinón-Torres, ${ }^{15,16}$ Sigita Burokienė, ${ }^{17}$ Tessa Goetghebuer, ${ }^{18}$ Vana Spoulou, ${ }^{19}$ Andrew Riordan, ${ }^{20}$ Cristina Calvo, ${ }^{21}$ Despoina Gkentzi, ${ }^{22}$ Markus Hufnagel, ${ }^{23}$ Peter J Openshaw, ${ }^{24}$ Menno D de Jong, ${ }^{25}$ Marion Koopmans, ${ }^{26}$ Herman Goossens, ${ }^{4}$ Margareta leven, ${ }^{4}$ Pieter L A Fraaij, ${ }^{27}$ Carlo Giaquinto, ${ }^{8}$ Julia A Bielicki, ${ }^{1,28}$ Peter Horby, ${ }^{5}$ Michael Sharland ${ }^{1}$

To cite: Kohns Vasconcelos M, Loens K, Sigfrid L, et al. Aetiology of acute respiratory infection in preschool children requiring hospitalisation in Europe-results from the PEDMERMAIDS multicentre case-control study. BMJ Open Resp Res 2021;8:e000887. doi:10.1136/ bmjresp-2021-000887

- Additional supplemental material is published online only. To view, please visit the journal online (http://dx.doi. org/10.1136/bmjresp-2021000887).

Received 29 January 2021 Accepted 5 July 2021

Check for updates

(C) Author(s) (or their employer(s)) 2021. Re-use permitted under CC BY-NC. No commercial re-use. See rights and permissions. Published by BMJ.

For numbered affiliations see end of article.

Correspondence to

Dr Malte Kohns Vasconcelos: mkohns@sgul.ac.uk

\section{ABSTRACT}

Background Both pathogenic bacteria and viruses are frequently detected in the nasopharynx (NP) of children in the absence of acute respiratory infection (ARI) symptoms. The aim of this study was to estimate the aetiological fractions for ARI hospitalisation in children for respiratory syncytial virus (RSV) and influenza virus and to determine whether detection of specific respiratory pathogens on NP samples was associated with ARI hospitalisation.

Methods 349 children up to 5 years of age hospitalised for ARI (following a symptom-based case definition) and 306 hospital controls were prospectively enrolled in 16 centres across seven European Union countries between 2016 and 2019. Admission day NP swabs were analysed by multiplex PCR for 25 targets.

Results RSV was the leading single cause of ARI hospitalisations, with an overall population attributable fraction (PAF) of $33.4 \%$ and high seasonality as well as preponderance in younger children. Detection of RSV on NP swabs was strongly associated with ARI hospitalisation (OR adjusted for age and season: 20.6, 95\% Cl: 9.4 to 45.3). Detection of three other viral pathogens showed strong associations with ARI hospitalisation: influenza viruses had an adjusted OR of 6.1 (95\% Cl: 2.5 to 14.9), parainfluenza viruses (PIVs) an adjusted OR of 4.6 (95\% Cl: 1.8 to 11.3$)$ and metapneumoviruses an adjusted $\mathrm{OR}$ of $4.5(95 \% \mathrm{Cl}$ : 1.3 to 16.1). Influenza viruses had a PAF of $7.9 \%$, PIVs of $6.5 \%$ and metapneumoviruses of $3.0 \%$. In contrast, most other pathogens were found in similar proportions in cases and controls, including Streptococcus pneumoniae, which was weakly associated with case status, and endemic coronaviruses.

\section{Key messages}

The study investigated which pathogens cause hospitalisation with acute respiratory infection (ARI) in preschool children in Europe

- Causes of children's ARls needing hospitalisation in Europe do not differ from other world regions. In upper airway samples, most pathogens, but not respiratory syncytial virus and influenza, are found at similar frequency in healthy and ill children.

ARIs are the most common reason for hospitalisation in children and are most commonly caused by viruses, not bacteria in this setting where pneumococcal conjugate vaccine use is common and influenza vaccine use is not common among young children.

Conclusion RSV is the predominant cause of ARI hospitalisations in young children in Europe and its detection, as well as detection of influenza virus, PIV or metapneumovirus, on NP swabs can establish aetiology with high probability. PAFs for RSV and influenza virus are highly seasonal and age dependent.

\section{INTRODUCTION}

The Global Burden of Disease Study 2015 estimates that acute respiratory infections (ARIs) cause more than $15 \%$ of under-five mortality. ${ }^{1}$ Approximately 102 million cases of 
pneumonia resulting in 0.7 million deaths occurred each year in children under 5 years of age. ${ }^{2}$ While compared with low-resource settings case fatality in paediatric ARI in Europe is much lower, ${ }^{3}$ ARI remains the most frequent reason for hospitalisation in children. ${ }^{4}$ In children under the age of 5 , respiratory viruses are detected in up to $80 \%$ of ARI cases. ${ }^{56}$ While Streptococcus pneumoniae remains the most prevalent bacterial pathogen, ${ }^{78}$ the proportion of bacterial ARI and prevalence of bacterial colonisation have declined with widespread use of conjugate vaccines. ${ }^{4-11}$ However, the frequency of treatment of ARI with antibiotics has not declined accordingly. ${ }^{12}$

Both in paediatric clinical care and research, nasopharyngeal (NP) samples are the only microbiological specimen that can routinely be obtained..$^{13}$ Children's upper airways are regularly colonised by potentially pathogenic bacteria or they are asymptomatic carriers of respiratory viruses. ${ }^{14}$ In a study on community-acquired pneumonia (CAP) among children in the USA, bacterial pathogens were identified in a minority of cases, with viruses, particularly respiratory syncytial virus (RSV) in younger and human rhinovirus (HRV) in older children, being identified in the majority. ${ }^{15}$ Codetection of viruses and bacteria is common. ${ }^{5716}$ Codetection has been associated with more severe disease in some, ${ }^{17} 18$ yet not in other studies. ${ }^{19}{ }^{20}$ Viral-bacterial codetection has mostly been shown to be associated with more severe disease, while codetection of several viruses was more often unrelated to severity. ${ }^{21}$ For S. pneumoniae, prevalence of upper airway colonisation peaks at around 3 years of age. ${ }^{22}$

Recent studies in Africa, Asia and North America, conducted in an era of widespread routine vaccination against encapsulated bacteria, show that the bulk of disease is caused by viral infections (predominantly RSV and HRV). ${ }^{1523}$ The Pneumonia Etiology Research for Child Health study compared more than 4000 children admitted for CAP with more than 5000 community controls in seven countries in sub-Saharan Africa and South-East Asia and in contrast to earlier findings, showed that RSV had by far the highest aetiological fraction $(31 \%)$ of all studied pathogens. ${ }^{23}$ Surprisingly, comparable data are not available for Europe. Both RSV and influenza viruses show distinct seasonal patterns in Europe. ${ }^{24}$ According to the European Centre for Disease Prevention and Control, pneumococcal conjugate vaccines (PCVs) have been introduced into routine infant vaccination schedules in the majority of European countries. However, influenza vaccines are only part of vaccination plans for children with increased risk, for example, due to comorbidities. Pronounced seasonality of ARI in Europe and potentially differing and changing epidemiology warranted a multicentre European study including cases hospitalised with ARI and healthy controls.

PREPARE (Platform for European Preparedness Against (Re-)emerging Epidemics) is a European Commission-funded network for harmonised large-scale clinical research studies on infectious diseases, prepared to rapidly respond to any severe infectious disease outbreak. The Multi-centre EuRopean study of MAjor Infectious Disease Syndromes (MERMAIDS) is the part of the PREPARE platform including case-control and cohort studies on aetiology and management of ARI.

The aim of this study was to estimate the aetiological fractions for ARI hospitalisation in children for RSV and influenza virus, both pathogens with a strongly seasonal occurrence in Europe, and to determine whether detection of specific respiratory pathogens in upper airway samples was associated with ARI hospitalisation. In line with the general mission of PREPARE, a secondary study aim was to build a European network of paediatric research sites trained and equipped for studies on ARIs in emergency care.

\section{METHODS}

\section{Study design}

The study was a case-control study with collection of clinical data and samples at baseline and follow-up of cases until discharge. Primary objective was to estimate the proportion of cases attributable to specific respiratory pathogens. Cases and controls were enrolled continuously throughout the year between September 2016 and March 2019 at 16 secondary or tertiary hospitals in seven European countries (Belgium, Germany, Greece, Italy, Lithuania, Spain and theUK). PCV was part of routine vaccination schedules within the first 6 months of life in all of these countries and influenza vaccines were not recommended as routine vaccines in any. Participants were recruited as they presented to paediatric departments, where they were screened for eligibility, mainly during daytime hours with high level of staffing. Total numbers of presenting eligible patients and number of screened patients were not systematically collected. Parents of all participants gave written informed consent and the study was approved by the responsible ethics committees at all sites. The study was designed to be as minimally invasive as possible and only pathogen detection samples were taken from all children. This protocol was written without patient involvement. Patients or guardians were not invited to comment on the study design or to contribute to the writing or editing of this document for readability or accuracy.

The protocol is available on the PREPARE website: https://prepare.ersnet.org/trials-protocols.aspx.

\section{Case and control groups}

Participants were otherwise healthy children under 6 years of age. Patients with temperature $\geq 38^{\circ} \mathrm{C}$ hospitalised due to a new episode of ARI according to a clinical definition were included in the study as cases. Controls were afebrile children attending the same hospitals for scheduled procedures or visits not related to infections and who did not fulfil clinical criteria for the case group but may have had mild symptoms of ARI. Hospital controls rather than community controls were chosen 
Table 1 Complete inclusion and exclusion criteria

Case group

Control group

Inclusion criteria

Age $<6$ years old on the day of admission

$\begin{array}{ll}\begin{array}{l}\text { Clinical suspicion of a new episode of ARI within the last } \\ 7 \text { days }\end{array} & \begin{array}{l}\text { One of the following } \\ \text { 1. Attending for an elective or semielective procedure } \\ \text { requiring general anaesthesia or moderate-deep sedation } \\ \begin{array}{l}\text { The attending physician has decided that the child requires } \\ \text { hospitalisation }\end{array} \\ \begin{array}{l}\text { (including, eg, surgery, radiological examinations etc). } \\ \text { Primary reason for hospital admission was clinical suspicion of }\end{array}\end{array} \begin{array}{l}\text { Well and otherwise healthy children attending an outpatient } \\ \text { clinic for a non-emergency clinical assessment. }\end{array}\end{array}$
a new episode of ARI

Temperature $\geq 38^{\circ} \mathrm{C}$ measured by any method (reported within Afebrile on the day of enrolment

24 hours or at presentation)

And at least two of the below (with at least one of 1 or 2):

1. Signs of lower respiratory tract infection: cough, abnormal sounds on chest auscultation (crackles, reduced breath sounds, bronchial breathing, wheezing), dyspnoea (chest indrawing, nasal flaring, grunting).

2. Signs of upper respiratory tract infection: coryza, nasal congestion, sore throat, pharyngitis, myringitis, acute otitis media.

3. Signs of respiratory dysfunction: tachypnoea for age or brady/apnoea or decreased oxygen saturation $(<92 \%$ in room air).

4. Signs of reduced general state: poor feeding, vomiting, lethargy/drowsiness.

No evidence of severe infection as judged by attending physician

Inpatient care for 24 hours or more for any condition within the previous 30 days, except for routine postnatal care Immunocompromised infant (stem cell transplant, solid organ transplant, HIV, AIDS, immunosuppressive therapy, primary immunodeficiency, haemodialysis)

Presence of complex chronic comorbidities ${ }^{39}$

Body weight $<3 \mathrm{~kg}$ on day of assessment and/or corrected gestational age $<37$ weeks

Aetiology other than infection (such as trauma, autoimmune Temperature $\geq 38^{\circ} \mathrm{C}$ or $<36^{\circ} \mathrm{C}$ disorder, malignancy) is suspected to be the primary cause of the current illness episode

Any signs and symptoms suggesting a clear primary focus of infection, such as urinary tract infection, open wounds, indwelling catheters, reactivation of previously diagnosed infectious or inflammatory condition

Dehydration due to previous illness episode such as diarrhoea and vomiting

ARI, acute respiratory infection.

for feasibility. To be included for the case-control study, an NP sample (as specified in the section on pathogen detection) had to be obtained. Eligibility criteria are listed in table 1. Matching of controls to cases by age, season and site of recruitment was attempted but not consistently successful.

\section{Pathogen detection}

NP swabs for pathogen detection were collected for cases and controls at admission (within 24 hours), or for some controls during an outpatient clinic visit. Samples were frozen at $-80^{\circ} \mathrm{C}$ until shipment to the central study laboratory at the University of Antwerp, where specimens were stored at $-80^{\circ} \mathrm{C}$ until analysis. NP samples were extracted with the NucliSens EasyMag (bioMérieux, France) by using the specific A protocol. The FTD Respiratory Pathogens 21 plus (Fast Track Diagnostics, Ltd, Luxembourg) was applied according to the instructions of the manufacturer for the qualitative detection of influenza A, influenza B, influenza A-H1N1, human coronaviruses NL63, 229E, OC43 and HKU1, parainfluenza viruses (PIVs) 1, 2, 3 and 4, human metapneumovirus A and B, HRV, RSV $\mathrm{A}$ and $\mathrm{B}$, adenovirus, enterovirus, parechovirus, bocavirus, Mycoplasma pneumoniae, Chlamydophila pneumoniae, S. pneumoniae, Haemophilus influenzae b and Staphylococcus aureus. 


\section{Data management and statistics}

Demographic data, focused medical history, clinical characteristics on admission, focused aspects of patient management and final outcome were entered into electronic case report forms hosted by the Julius Center at the University of Utrecht. Data were checked for completeness at the end of the study and data queries completed within 6 months of inclusion of the last participant.

The sample size was determined before the study started based on estimates for the proportions of children who were positive for RSV and influenza virus. With an expected positive proportion for influenza of $10 \%$ in cases and 3\% in controls and aiming for $90 \%$ power and alpha $=5 \%$ for an OR larger than 1.0, the required sample size for influenza was 320 per group. The required sample size for RSV was 40 per group (expected $25 \%$ positive in cases and $1 \%$ in controls). As these sample sizes were not additional, the total required sample size followed the calculation for influenza and was therefore 640 (320 cases and 320 controls).

Data handling and statistical operations were performed in Stata V.14. Complete records analysis was done throughout, as missing data were rare (below 5\% on individual variables, none on pathogen detection and no dropped observations on covariate analyses). For categorical variables, $p$ values were obtained by $\chi^{2}$ test and for continuous variables by Wilcoxon rank-sum test due to the non-normal distribution of their values. Necessitated by incomplete matching, adjusted ORs were calculated by logistic regression with age and season of recruitment as covariates, $\mathrm{p}$ values were obtained by Wald test. For adjusted ORs, sensitivity analyses were performed to explore if these differed based on (1) coadjusting for country of inclusion, because proportions of cases and controls among the participants differed by country and (2) using a control group restricted to completely asymptomatic children. The population attributable fraction (PAF) was calculated by substituting the OR for the risk ratio where detection of the pathogen in the control group was sufficiently rare to allow for this substitution. ${ }^{25}$

\section{RESULTS}

A total of 349 cases and 306 controls were enrolled from 16 sites in seven countries during the study period, with approximately three-quarters of cases and two-thirds of controls enrolled in the main European ARI season between October and March. Sixty-one per cent of participants were male, with cases slightly younger than controls. The proportions of cases and controls included in the participating countries differed (table 2).

\section{Clinical course}

In cases, the median time to presentation in the emergency department, from first day of onset of symptoms was 2 days (IQR: $1-4$ ). The most common symptom on presentation was poor feeding, seen in 241 (69.3\%), 190 $(54.4 \%)$ had chest recessions, 137 (39.4\%) wheezing and
$109(31.2 \%)$ had a fever of $>39^{\circ} \mathrm{C}$. A relevant proportion of cases had signs of more severe disease: 26 (7.5\%) required supplemental oxygen on admission and 12 $(3.5 \%)$ had a central capillary refill time of $>2 \mathrm{~s}$. Of the controls, $33(10.8 \%)$ had mild illness as reported by parents during the previous 7 days but did not fulfil inclusion criteria as a case.

The majority of cases had disease clinically classified as lower respiratory tract infection (LRTI). About $59.3 \%$ of cases were treated with antibiotics during their admission. Among cases diagnosed as LRTI, $68.6 \%$ received antibiotics, compared with $34.8 \%$ among children with upper respiratory tract infection (URTI) and $35.7 \%$ with unspecified infection.

\section{Detected potential pathogens in cases and controls}

Figure 1A shows prevalence of detection of respiratory pathogens in study samples. S. pneumoniae was the most prevalent target detected in cases and controls. The second most frequent potentially pathogenic bacteria found was $S$. aureus, which was the only one weakly associated with being a control rather than a case (OR for case status: $0.7,95 \%$ CI: 0.5 to 1 ).

Respiratory viruses were detected in $>80 \%$ of cases and $>40 \%$ of controls. The respiratory virus most frequently detected was HRV, which was found in $>20 \%$ of both cases and controls. Eighty per cent (32 of 40) of the detected influenza viruses were influenza $\mathrm{A}$, among these $22(68.8 \%)$ were influenza A-H1N1. All influenza $\mathrm{B}$ were isolated from children in the case group, but due to the small number of isolates this may likely be random.

Human coronaviruses were detected at similar frequencies, between $5 \%$ and $10 \%$, in both cases and controls and showed no predominance for any age (median age in years among coronavirus negative: 1.39, IQR: 0.49 to 3.20 ; among coronavirus positive: 1.34, IQR: 0.59 to $2.40 ; \mathrm{p}=0.642$ ). All four endemic coronaviruses were evenly distributed between cases and controls (229E in 7 cases and 5 controls, NL63 in 3 cases and 5 controls, HKU1 in 4 cases and 7 controls and OC43 in 8 cases and 10 controls).

Codetection of potentially pathogenic bacteria and viruses was common in both groups $(51.9 \%$ in cases and $28.8 \%$ in controls). Among the 187 cases in which both bacteria and viruses were found, RSV was found in 74 and influenza virus in 16. S. pneumoniae was the bacterial potential pathogen found in most codetection cases $(83.4 \%)$ and $S$. aureus was detected in $32.1 \%$. In contrast, among controls with detection of both viruses and bacteria simultaneously, only very few carried RSV or influenza virus ( 7 and 3 , respectively) but 43 (48.9\%) carried rhinovirus and proportions positive for $S$. pneumoniae $(87.5 \%)$ and S. aureus $(38.6 \%)$ were similar as in cases.

Other respiratory pathogens were detected in only very low proportions of participants: M. pneumoniae in three 


\begin{tabular}{|c|c|c|c|}
\hline Groups & ARI & Control & $P$ value \\
\hline Total inclusions (N) & 349 & 306 & - \\
\hline Sex (male, n, \%) & $202(57.9)$ & $200(65.4)$ & $<0.001$ \\
\hline Age in years (median, IQR) & $1.09(0.42$ to 2.49$)$ & 1.80 (0.93 to 3.65$)$ & $<0.001$ \\
\hline \multicolumn{4}{|l|}{ Age range $(\mathrm{n}, \%)$} \\
\hline$<12$ months & $160(45.9)$ & $83(27.1)$ & \multirow[t]{3}{*}{$<0.001$} \\
\hline $12-<36$ months & $120(34.4)$ & $114(37.3)$ & \\
\hline$\geq 36$ months & 69 (19.8) & $109(35.6)$ & \\
\hline \multicolumn{4}{|l|}{ Inclusion by season (n, \%) } \\
\hline October-December & $76(21.8)$ & $85(27.8)$ & \multirow[t]{3}{*}{$<0.001$} \\
\hline January-March & $182(52.2)$ & $115(37.6)$ & \\
\hline April-September & $91(26.1)$ & $106(34.6)$ & \\
\hline \multicolumn{4}{|l|}{ Inclusion by country (n, \%) } \\
\hline Greece & $144(41.3)$ & 50 (16.3) & \multirow[t]{5}{*}{$<0.001$} \\
\hline Italy & $85(24.4)$ & $46(15.0)$ & \\
\hline Spain & 45 (12.9) & $45(14.7)$ & \\
\hline UK & $55(15.8)$ & $94(30.7)$ & \\
\hline Other & $20(5.7)$ & 71 (23.2) & \\
\hline Symptom onset prior to inclusion in days (median, IQR) & $2(1$ to 4$)$ & - & - \\
\hline IVF during inpatient stay (n, \%) & $184(52.7)$ & - & - \\
\hline Antibiotic treatment (n, \%) & $207(59.3)$ & - & - \\
\hline PICU admission & $9(2.6)$ & - & - \\
\hline Length of hospital stay in days (median, IQR) & 3 (2 to 5$)$ & - & - \\
\hline \multicolumn{4}{|l|}{ Clinician diagnosis at discharge } \\
\hline URTI & $69(19.8)$ & - & \multirow[t]{3}{*}{-} \\
\hline LRTI & $245(70.2)$ & - & \\
\hline Unspecified & $35(10.0)$ & - & \\
\hline Died (n, \%) & $0(0.0)$ & - & - \\
\hline
\end{tabular}

$P$ values were obtained using $\chi^{2}$ test or Wilcoxon rank-sum test as applicable.

$A R I$, acute respiratory infection; IQR, interquartile range

; IVF, intravenous fluid; LRTI, lower respiratory tract infection; PICU, paediatric intensive care unit; URTI, upper respiratory tract infection.

cases $(0.9 \%)$ and no controls, C. pneumoniae was not detected in any cases but in three controls $(1.0 \%)$ and $H$. influenzae $b$ was not detected in either group.

No potential respiratory pathogen was detected in only $27.1 \%$ of controls and $4.3 \%$ of cases. Figure $1 \mathrm{~B}$ illustrates clear evidence of a higher frequency of detection of RSV (OR: 23.0, 95\% CI: 10.5 to 59.2), influenza virus (OR: 5.4, 95\% CI: 2.2 to 15.9 ), PIV (OR: $4.5,95 \%$ CI: 1.8 to 13.5 ) and metapneumovirus (OR: $4.2,95 \% \mathrm{CI}$ : 1.2 to 23.1) in cases compared with controls.

Proportions of patients with detection of no pathogen, only bacteria, only viruses or both viruses and bacteria did not change depending on prior duration of symptoms in days $(\mathrm{p}=0.502)$.

There was no difference in the frequency of antibiotic prescriptions when comparing different groups of detected pathogens. Antibiotics were given in $62.5 \%$ of children with no pathogen detected, $65.7 \%$ with only bacteria detected, $63.6 \%$ with only viruses detected and $52.9 \%$ with viruses and bacteria detected $(p=0.158)$. There was no difference in prevalence of antibiotics in children who tested positive for RSV (61.3\% received antibiotics, compared with $56.5 \%$ in RSV negative, $\mathrm{p}=0.637$ ) or positive for influenza virus $(56.9 \%$ received antibiotics, compared with $55.8 \%$ in influenza negative, $\mathrm{p}=0.479)$.

\section{Age and season dependency of pathogen detection}

Table 3 presents the breakdown of detection of RSV, influenza, parainfluenza, metapneumovirus and S. pneumoniae. As expected, RSV was more commonly found in younger children and almost $90 \%$ of detection of influenza virus occurred between January and March. PIV was more often detected in children of the two younger age groups and in autumn or summer as compared with 


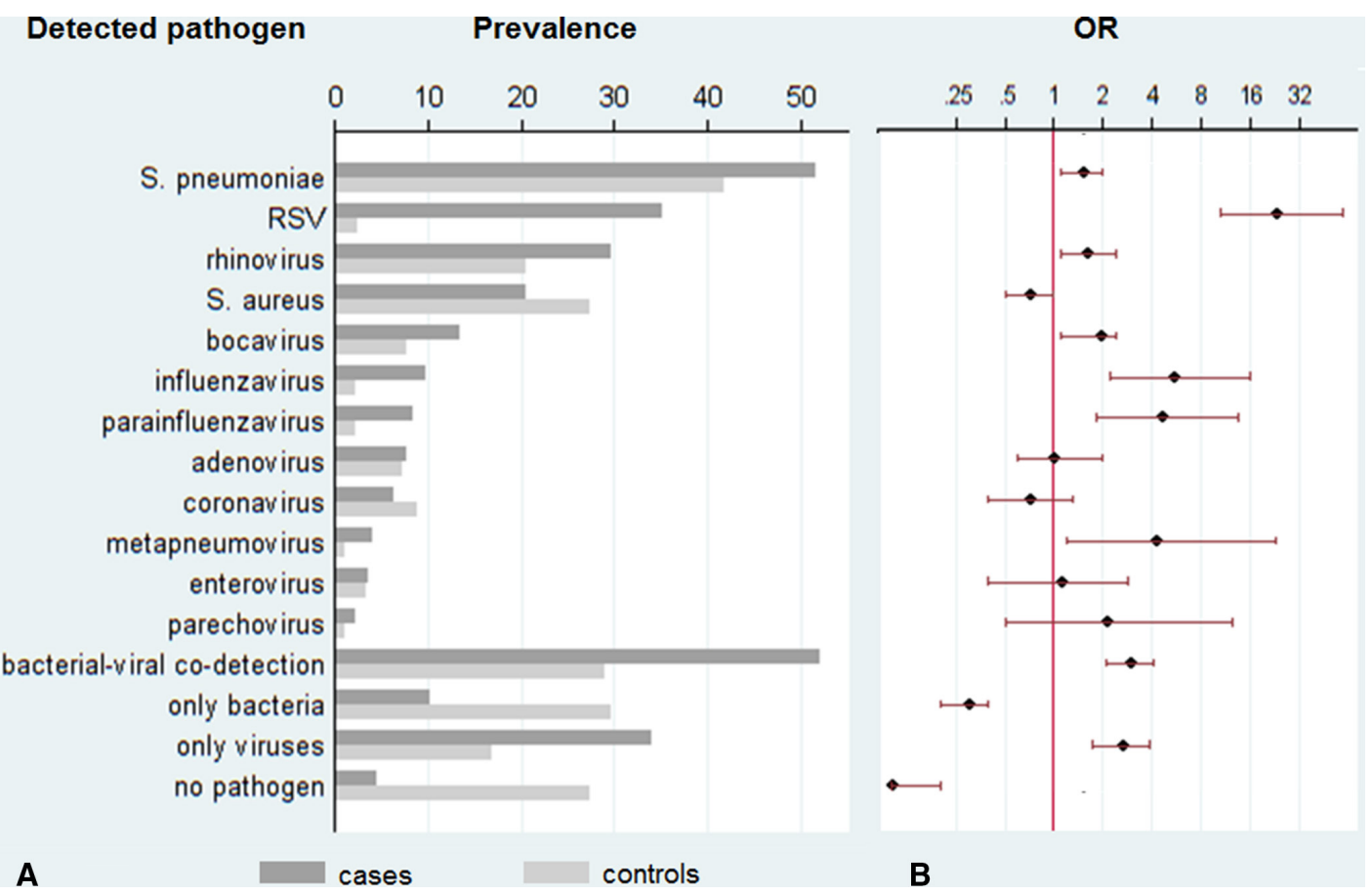

Figure 1 Prevalence of respiratory pathogens or combinations (A) and respective ORs for detection (B). (A) Prevalence of respiratory pathogens in nasopharyngeal swabs at hospital admission in percent, dark grey bars for cases, light grey bars for controls. (B) ORs with 95\% Cls for detection in cases compared with controls. RSV, respiratory syncytial virus.

winter. Detection of metapneumovirus was evenly distributed among age groups and seasons.

Additionally, online supplemental table 1 provides numbers and proportions of participants with detection of all pathogens presented in figure 1 by case or control status. Parechovirus was more often detected in cases in autumn (6.6\%, compared with $1.1 \%$ in winter and $0 \%$ in summer, $\mathrm{p}=0.011$ ) and enterovirus more often in summer $(8.8 \%$, compared with $1.3 \%$ in autumn and $1.7 \%$ in winter, $\mathrm{p}=0.011)$. Other pathogens showed no distinct seasonality.
Because both age and season of recruitment were distributed differently between cases and controls, we calculated OR estimates adjusted for these covariates. As shown in table 4, the adjusted ORs did not differ markedly from the crude ORs presented in figure 1B. Detection of RSV was very strongly associated with being a case (OR: 20.6). To a lesser degree, this is also true for influenza virus (OR: 6.1), PIV (OR: 4.6) and metapneumovirus (OR: 4.5). For S. pneumoniae, the association of detection and case status was weaker (OR: 1.7). The sensitivity analysis including country of inclusion

\begin{tabular}{|c|c|c|c|c|c|c|}
\hline & \multicolumn{3}{|c|}{ Age group } & \multicolumn{3}{|l|}{ Season } \\
\hline & $\begin{array}{l}<12 \\
\text { Months }\end{array}$ & $\begin{array}{l}12-<36 \\
\text { Months }\end{array}$ & $\begin{array}{l}\geq 36 \\
\text { Months }\end{array}$ & October-December & January- March & April- September \\
\hline $\begin{array}{l}\text { Streptococcus } \\
\text { pneumoniae, n (\%) }\end{array}$ & $\begin{array}{l}102 \\
(42.0)\end{array}$ & $\begin{array}{l}107 \\
(45.7)\end{array}$ & $\begin{array}{l}101 \\
(54.6)\end{array}$ & $\begin{array}{l}79 \\
(49.1)\end{array}$ & $\begin{array}{l}131 \\
(44.1)\end{array}$ & $\begin{array}{l}96 \\
(48.7)\end{array}$ \\
\hline RSV, n (\%) & $\begin{array}{l}74 \\
(30.5)\end{array}$ & $\begin{array}{l}40 \\
(17.1)\end{array}$ & $\begin{array}{l}17 \\
(9.2)\end{array}$ & $\begin{array}{l}30 \\
(18.6)\end{array}$ & $\begin{array}{l}84 \\
(28.3)\end{array}$ & $\begin{array}{l}15 \\
(7.6)\end{array}$ \\
\hline Influenza virus, n (\%) & $\begin{array}{l}16 \\
(6.6)\end{array}$ & $\begin{array}{l}10 \\
(4.3)\end{array}$ & $\begin{array}{l}14 \\
(7.6)\end{array}$ & $\begin{array}{l}3 \\
(1.9)\end{array}$ & $\begin{array}{l}35 \\
(11.8)\end{array}$ & $\begin{array}{l}2 \\
(1.0)\end{array}$ \\
\hline Parainfluenza virus, $\mathrm{n}(\%)$ & $\begin{array}{l}13 \\
(5.4)\end{array}$ & $\begin{array}{l}15 \\
(6.4)\end{array}$ & $\begin{array}{l}7 \\
(3.9)\end{array}$ & $\begin{array}{l}14 \\
(8.7)\end{array}$ & $\begin{array}{l}9 \\
(3.0)\end{array}$ & $\begin{array}{l}12 \\
(6.1)\end{array}$ \\
\hline Metapneumovirus, n (\%) & $\begin{array}{l}6 \\
(2.5)\end{array}$ & $\begin{array}{l}7 \\
(3.0)\end{array}$ & $\begin{array}{l}4 \\
(2.3)\end{array}$ & $\begin{array}{l}0 \\
(0.0)\end{array}$ & $\begin{array}{l}10 \\
(3.4)\end{array}$ & $\begin{array}{l}7 \\
(3.6)\end{array}$ \\
\hline No pathogen, n (\%) & $\begin{array}{l}35 \\
(14.4)\end{array}$ & $\begin{array}{l}34 \\
(14.5)\end{array}$ & $\begin{array}{l}30 \\
(16.2)\end{array}$ & $\begin{array}{l}27 \\
(16.8)\end{array}$ & $\begin{array}{l}34 \\
(11.5)\end{array}$ & $\begin{array}{l}37 \\
(18.8)\end{array}$ \\
\hline
\end{tabular}

RSV, respiratory syncytial virus. 
Table 4 OR of detection in cases compared with controls by multiplex PCR in nasopharyngeal swabs, by pathogen, adjusted for age and season (logistic regression)

\begin{tabular}{lccc}
\hline Pathogen & $\begin{array}{l}\text { Adjusted } \\
\text { OR }\end{array}$ & $\mathbf{9 5 \%} \mathbf{C l}$ & P value \\
\hline $\begin{array}{l}\text { Streptococcus } \\
\text { pneumoniae }\end{array}$ & 1.7 & 1.2 to 2.3 & 0.002 \\
RSV & 20.6 & 9.4 to 45.3 & $<0.001$ \\
Influenza virus & 6.1 & 2.5 to 14.9 & $<0.001$ \\
Parainfluenza virus & 4.6 & 1.8 to 11.3 & 0.001 \\
Metapneumovirus & 4.5 & 1.3 to 16.1 & 0.021 \\
$\begin{array}{l}\text { No pathogen } \\
\text { detected }\end{array}$ & 0.1 & $<0.1$ to 0.2 & $<0.001$ \\
\hline
\end{tabular}

$P$ values were obtained by Wald test.

RSV, respiratory syncytial virus.

as a covariate indicated that, after multivariate adjustment, country of inclusion had no effect on the association between pathogens and case status (table 5). When restricting the analysis to controls without any symptoms of respiratory infection, ORs for S. pneumoniae and influenza virus remained similar, but the association between detection of RSV or metapneumovirus and case status became even more pronounced (RSVOR: 42.6, metapneumovirus-OR: 6.2).

\section{Age-specific and season-specific PAF estimates}

As $S$. pneumoniae (and some respiratory viruses including HRV) were commonly detected in controls, PAF was not estimated. For RSV, the overall PAF was $33.4 \%$ and for influenza virus $7.9 \%$. Due to the specific distribution characteristics of these viruses there were, however, marked differences between the PAF estimates for different age groups and at different times of the year (table 6). For PIV, the overall PAF was $6.5 \%$ and for metapneumovirus $3.0 \%$. Estimation of age-group and season-specific PAF was unfeasible due to low overall detection numbers.

Between the months of October and March, RSV caused close to $50 \%$ of ARI hospitalisation in children under the

\begin{tabular}{|c|c|c|c|}
\hline & \multicolumn{3}{|c|}{ Age group (PAF\%) } \\
\hline & $\begin{array}{l}<12 \\
\text { Months }\end{array}$ & $\begin{array}{l}12-<36 \\
\text { Months }\end{array}$ & $\begin{array}{l}\geq 36 \\
\text { Months }\end{array}$ \\
\hline \multicolumn{4}{|l|}{ RSV } \\
\hline \multicolumn{4}{|l|}{ Season } \\
\hline October-December & 48.0 & 38.1 & 20.0 \\
\hline January-March & 48.1 & 35.6 & 19.2 \\
\hline April-September & 23.5 & 16.7 & 4.8 \\
\hline \multicolumn{4}{|l|}{ Influenza virus } \\
\hline \multicolumn{4}{|l|}{ Season } \\
\hline October-December & $-{ }^{*}$ & 8.0 & 3.8 \\
\hline January-March & 11.0 & 9.5 & 30.3 \\
\hline April-September & 3.0 & $-^{*}$ & 4.8 \\
\hline
\end{tabular}

No estimates for S. pneumoniae are presented due to its high prevalence in the control group (see Methods for details) and for PIV and metapneumovirus due to low overall detection numbers.

${ }^{*}$ None detected in cases or controls.

PAF, population attributable fraction; RSV, respiratory syncytial virus.

age of 1 and a third of ARI hospitalisation in children aged 2-3 years in this study. These fractions did not differ between the autumn months (October-December) and winter months (January-March). In contrast, the PAF for influenza virus was highest in winter and in children over the age of 3 years, where influenza virus caused a third of ARI hospitalisations.

\section{DISCUSSION}

The aetiology of severe ARI requiring hospitalisation in children from this European case-control study is consistent with previously reported results from other settings. ${ }^{152}$ These findings show that RSV was the dominant respiratory pathogen in preschool children during the study period, causing a third of ARI

Table 5 Sensitivity analyses for OR of detection in cases compared with controls, by pathogen, adjusted for age and season (logistic regression)

\begin{tabular}{|c|c|c|c|c|c|c|}
\hline \multirow[b]{2}{*}{ Pathogen } & \multicolumn{3}{|c|}{ Additionally adjusted for country of inclusion } & \multicolumn{3}{|c|}{ Excluding mildly symptomatic controls } \\
\hline & Adjusted OR & $95 \% \mathrm{Cl}$ & $P$ value & Adjusted OR & $95 \% \mathrm{Cl}$ & $P$ value \\
\hline $\begin{array}{l}\text { Streptococcus } \\
\text { pneumoniae }\end{array}$ & 1.63 & 1.17 to 1.27 & 0.003 & 1.95 & 1.39 to 2.73 & $<0.001$ \\
\hline RSV & 20.7 & 9.38 to 45.82 & $<0.001$ & 42.6 & 13.31 to 136.29 & $<0.001$ \\
\hline Influenza virus & 6.38 & 2.56 to 15.88 & $<0.001$ & 6.38 & 2.42 to 16.81 & $<0.001$ \\
\hline Parainfluenza virus & 4.87 & 1.93 to 12.28 & 0.001 & 4.02 & 1.63 to 9.96 & 0.003 \\
\hline Metapneumovirus & 4.04 & 1.10 to 14.79 & 0.035 & 6.20 & 1.37 to 28.02 & 0.018 \\
\hline No pathogen detected & 0.12 & 0.07 to 0.22 & $<0.001$ & 0.10 & 0.05 to 0.18 & $<0.001$ \\
\hline
\end{tabular}

$P$ values were obtained by Wald test.

RSV, respiratory syncytial virus. 
hospitalisations. Detection of RSV in healthy children was rare. In our study, half of ARI hospitalisations could be attributed to the four pathogens with the strongest association with ARI hospitalisation, that is, RSV, influenza virus, PIV and metapneumovirus.

Both RSV and influenza virus are highly seasonal, and their prevalence was associated with patient age. However, the strength of their association with being hospitalised for ARI did not differ between age groups and seasons. This suggests that their detection is highly predictive for aetiology of an ARI episode even in patients who are not part of the typical risk group (ie, infants for RSV) or who present outside the pathogen's main season. Compared with data from studies set in sub-Saharan Africa and South-East Asia, influenza viruses were more commonly detected in children hospitalised for ARI in this study. ${ }^{723}$ While the PAF is therefore higher in Europe, the association of detected virus with clinical disease was similar across settings. ${ }^{23}$ PIV was more often detected in autumn and summer compared with the winter months when most patients with ARI are hospitalised. This suggests that it may have a high PAF in months with a lower frequency of cases. However, numbers of PIV detection were too low in this study to demonstrate this.

$S$. pneumoniae was the most frequently detected respiratory pathogen in NP swabs from both children hospitalised for ARI and healthy controls but was not a strong predictor of hospitalisation for ARI. This is consistent with previous findings of an age-related dynamic with high nasopharyngeal colonisation rate by $S$. pneumoniae in infancy and early childhood..$^{22}$ Therefore, detection of $S$. pneumoniae on upper airway samples is unable to reliably establish the aetiology of an ARI episode. $S$. aureus was more frequently found in control children. S. aureus may cause LRTIs and is especially common as a cause of superinfections following influenza. However, its detection in NP specimens was not indicative of ARI. An inverse relationship between carriage of $S$. pneumoniae and $S$. aureus may explain this finding due to $S$. pneumoniae being a more common cause of ARI. This has been suggested, but study results are contradictory. ${ }^{26} 27$

The higher proportion of codetection of viruses and bacteria in cases as compared with controls was almost exclusively accounted for by higher proportions of children infected with RSV or influenza virus. Thus, the association between codetection of viruses and bacteria with being hospitalised for ARI in our study likely reflects the importance of viruses in causing severe respiratory symptoms in young children rather than suggesting true co-infections.

The low rate of detection of less-common causes of pneumonia, such as M. pneumoniae and C. pneumoniae, is likely due to the generally low prevalence of these pathogens in the studied age group. ${ }^{28}$ The absence of $H$. influenzae $b$ is not surprising, as carriage and infections have virtually disappeared since the introduction of the vaccine. ${ }^{29}$
This study ended before the beginning of the current COVID-19 pandemic. The four previously endemic coronaviruses were found in similar and low proportions in both cases and controls and were not associated with case status. Therefore, although they may have caused ARI hospitalisation in some children, their detection on NP swabs was not sufficient to establish them as causative pathogens of ARI.

The study's aim of capacity building proved to be crucial regarding the current pandemic. With the onset of the pandemic, the study network was instantly able to provide information on patient management strategies and to facilitate site participation in the WHO-initiated ISARIC Clinical Characterisation Protocol. ${ }^{30}{ }^{31}$ Further, several study sites are participating in subsequently launched consortia funded by the European Commission.

A limitation of this study is that we only analysed upper airway samples. Previous multiplex PCR-based studies confirmed a high concordance between respiratory pathogens found in upper and lower airways, but especially with regard to specific pathogens discordance has been reported. ${ }^{32-34}$ By restricting the samples to NP samples, the study may still have missed a stronger association of lower airway carriage of bacteria with ARI hospitalisation. Nevertheless, restricting samples to NP swabs best reflects the situation in paediatric clinical care.

Another important limitation is that we did not systematically record numbers of screened patients and that both cases and controls were convenience samples. Because of differing thresholds for patient admission it is difficult to compare severity of disease in hospitalised children with ARI between high-resource and low-resource settings, but on average hospitalised children in high-resource settings have milder disease. ${ }^{35}$ Very few children in our sample required intensive care unit treatment on admission, and this is consistent with the low case fatality of childhood ARI in high-resource settings. ${ }^{3}$ Poor feeding was the most frequently observed clinical ARI sign. Poor feeding can be seen in the majority of children with RSV bronchiolitis and is often the cause for hospitalisation. ${ }^{36}$ In terms of disease severity, the group of cases in our study does not seem to differ from children included in other studies on hospitalisations for ARI (including, but not exclusively, CAP) in comparable settings. ${ }^{37}$ Although overall case severity showed a good representation of the intended group, it is nonetheless possible that convenience sampling biased associations between detected pathogens and hospitalisation in either direction.

The study was conducted in a setting where in all places PCV was part of routine infant vaccine schedules and influenza vaccine was not. Therefore, the study cannot provide evidence on the effect of these vaccines on aetiology of childhood ARI hospitalisation and may not be generalisable to settings with differing vaccination schedules. 
Hospital controls are less likely to have symptoms than children in the community, as those with symptoms may not attend hospital visits or may postpone elective procedures. Children were still included in the control group if they showed symptoms of mild disease as long as they did not meet case criteria as this has been shown to result in a control group most representative of the general population. ${ }^{14}$ Exclusion of controls with mild respiratory symptoms would lead to an overestimation of the association between pathogens and hospitalisation, especially for pathogens rarely found in asymptomatic children. Some overestimation of these associations may still have occurred due to the choice of hospital controls rather than community controls.

This study is the first to present findings on the aetiology of hospitalisations for ARI applying the same protocol across sites in seven European countries. The results illustrate that the causes of severe ARI requiring hospital admission do not differ profoundly between these European and other global settings. However, the pronounced seasonality of circulation of RSV and influenza virus as major causal agents leads to differing probabilities of infection with these pathogens in an individual patient, strongly depending on age and time of year.

Previous studies have shown that reduction of inappropriate antibiotic prescriptions in emergency departments can be achieved with antibiotic stewardship programmes. ${ }^{38}$ Our study provides evidence that detection of RSV and influenza virus on NP samples can strongly support a suspected viral aetiology of ARI and may therefore help to reduce antibiotic prescriptions.

\section{Author affiliations}

${ }^{1}$ Paediatric Infectious Diseases Research Group, Institute for Infection and Immunity, St. George's, University of London, London, UK

${ }^{2}$ Institute for Medical Microbiology and Hospital Hygiene, Heinrich Heine University Düsseldorf, Düsseldorf, Germany

${ }^{3}$ Laboratory of Clinical Microbiology, Antwerp University Hospital, Edegem, Belgium

${ }^{4}$ Laboratory of Medical Microbiology, Vaccine \& Infectious Disease Institute (VAXINFECTIO), University of Antwerp, Antwerp, Belgium

${ }^{5}$ Centre for Tropical Medicine and Global Health, Nuffield Department of Medicine, University of Oxford, Oxford, UK

${ }^{6}$ Infectious Diseases Unit, 3rd Department of Paediatrics, Aristotle University School of Health Sciences, Hippokration General Hospital, Thessaloniki, Greece

${ }^{7}$ Paediatric Infectious Diseases Unit, Department of Paediatrics, Hospital Universitario 12 de Octubre and Red de Investigación Traslacional en Infectología Pediátrica (RITIP), Instituto de Investigación 12 de Octubre (imas12), Madrid, Spain

${ }^{8}$ Division of Paediatric Infectious Diseases, Department of Women's and Children's Health, University Hospital of Padua, Padova, Italy

${ }^{9}$ Paediatric Emergency Department, Department of Women's and Children's Health, University Hospital of Padua, Padova, Italy

${ }^{10} \mathrm{NIHR}$ Southampton Biomedical Research Centre, University of Southampton and University Hospital Southampton NHS Foundation Trust, Southampton, UK

${ }^{11}$ 2nd Department of Paediatrics, National and Kapodistrian University of Athens (NKUA) School of Medicine, P. and A. Kyriakou Children's Hospital, Athens, Greece

${ }^{12}$ Paediatric Department, University Hospital Lewisham, Lewisham and Greenwich NHS Trust, London, UK
${ }^{13}$ Department of Paediatric Cardiology, Pulmonology and Intensive Care Medicine, University Children's Hospital Tübingen, Tübingen, Germany ${ }^{14}$ Clinical Pathways and Epidemiology Unit, IRCCS Bambino Gesù Children's Hospital, Rome, Italy

${ }^{15}$ Translational Paediatrics and Infectious Diseases, Hospital Clínico Universitario de Santiago, Servizo Galego de Saude, Santiago de Compostela, Spain

${ }^{16}$ Genetics, Vaccines and Infectious Diseases Research Group, Instituto de Investigación Sanitaria de Santiago, Universidade de Santiago de Compostela, Santiago de Compostela, Spain

${ }^{17}$ Clinic of Children's Diseases, Institute of Clinical Medicine, Vilnius University, Vilnius, Lithuania

${ }^{18}$ Department of Paediatrics, St-Pierre Hospital Brussels, Brussels, Belgium

${ }^{19} 1$ st Department of Paediatrics, National and Kapodistrian University of Athens (NKUA) School of Medicine, Agia Sophia Children's Hospital of Athens, Athens, Greece

${ }^{20}$ Department of Paediatric Infectious Diseases, Alder Hey Children's Hospital, Liverpool, UK

${ }^{21}$ Paediatrics and Infectious Diseases Department, La Paz University Hospital, Madrid, Spain

${ }^{22}$ Department of Paediatrics, University General Hospital of Patras, Patras Medical School, Patras, Greece

${ }^{23}$ Division of Paediatric Infectious Diseases and Rheumatology, Department of Paediatrics and Adolescent Medicine, University Medical Centre, Medical Faculty, University of Freiburg, Freiburg, Germany

${ }^{24}$ National Heart and Lung Division, Faculty of Medicine, Imperial College London, London, UK

${ }^{25}$ Department of Medical Microbiology, Amsterdam UMC, Amsterdam, The Netherlands

${ }^{26}$ Department of Viroscience, ErasmusMC, Rotterdam, The Netherlands

${ }^{27}$ Sophia Children's Hospital, ErasmusMC, Rotterdam, The Netherlands

${ }^{28}$ Department of Infectious Diseases and Vaccinology, University of Basel Children's Hospital (UKBB), Basel, Switzerland

Acknowledgements The authors would like to thank all parents and participants for their contribution and support of the study. PED-MERMAIDS ARI case-control study group: Fondazione Penta Onlus (study sponsor) - Carlo Giaquinto, Daniel Gomez Pena, Markela Koniordou; Saint George's Hospital London - Michael Sharland, Julia A. Bielicki, Malte Kohns Vasconcelos, Jessica Jarvis, Elena Stefanova, Kamila Kalka, Claire Womack, Elia Vitale, Samsul Islam; Alder Hey Children's Hospital Liverpool - Andrew Riordan, Liz Lee, Rachel GreenwoodBibby; Hospital Universitario 12 de Octubre Madrid - Pablo Rojo, Cristina Epalza, Manuel Gijon, Carmen Troyano, Fátima Machín and Måuz Romero; Hospital Clínico Universitario de Santiago - Federico Martinón-Torres, Carmen Rodríguez-Tenreiro Sánchez, Irene Rivero-Calle, Antonio Justicia-Grande, Lorenzo Redondo-Collazo, Miriam Cebey-López, Marta Lendoiro Fuentes, Beatriz Morillo; P.and A. Kyriakou Children's Hospital - Maria Tsolia, Aggeliki Syggelou, Maria-Helen Papatesta; Hippokration Hospital of Thessaloniki - Emmanuel Roilides, Elias losifidis, Savvas Papachristou, Katerina Vikelouda, Athina Giampani, Ioanna Stamouli; Bambino Gesù Children's Hospital - Marta Ciofi degli Atti, Carmen D'Amore, Maia de Luca, Livia Gargiullo, Susanna Livadiotti, Anna Chiara Vittucci; University Medical CenterCentre Freiburg - Markus Hufnagel, Mirjam Freudenhammer, Bianca Rippberger, Anita Imm; Clinic of Children's Diseases, Institute of Clinical Medicine, Vilnius University, Lithuania - Vytautas Usonis, Sigita Burokiene, Inga Ivaskeviciene, Bozena Paskevic; University Hospital of Padua - Daniele Donà, Chiara Minotti, Liviana Da Dalt, Federica Savio; University Hospital Lewisham - Maggie Nyirenda Nyang'wa, Sophie Keers, Samia Pilgrim, Emma Gardiner; CHU Saint-Pierre Brussels - Tessa Goetghebuer, Alejandra Saravia Vidaurre; Universitätsklinikum Tübingen - Hanna Renk, Anna-Lena Gemmel, Steffen Wiechers; University Hospital of Patras Despoina Gkentzi, Gabriel Dimitriou, Eleni Papachatzi, Kalliopi Konstantinopoulou, Sophia Leventeli; Hospital Universitario La Paz Madrid - Cristina Calvo, Maria de Ceano-Vivas, Talía Sainz, Vega Mauleón;Agia Sophia Children's Hospital of Athens Vana Spoulou, Joanna Papadatou, Irene Tzovara

Contributors LS, ER, PR, JJ, MT, MCdA, FM-T, AR, PJO, MDdJ, MK, HG, MI, PLAF, $\mathrm{CG}, \mathrm{JAB}, \mathrm{PH}$ and $\mathrm{MS}$ were responsible for conception and design of the study. Data collection was done by MKV, KL, EI, CE, DD, VM, SP, MG, CM, LDD, SI, JJ, AS, MNN, SK, HR, A-LG, CD'A, CR-TS, SB, TG, VS, AR, CC, DG and MH. Data analysis and interpretation were done by MKV, KL, LS, JAB and MS. MKV and KL were responsible for drafting the article. Critical revision of the article was done by LS, El, CE, ER, MNN, FM-T, AR, PLAF, JAB, PH and MS. All authors gave final approval of the version to be published. 
Funding This project has received funding from the European Union's Seventh Framework Programme for research, technological development and demonstration (FP7) under grant agreement No. HEALTH-F3-2013-602525.

Competing interests Other than funds through the project grant, no payment was received by any authors in relation to this study. The funder was not involved in the design, conduct, analysis and interpretation of the data, nor in the writing and the decision to submit the paper. Outside the presented work, the authors disclose the following activities and remunerations: CE is on the advisory board for Viiv and she received travel grants from Gilead; PJO received personal fees from his work as a consultant or scientific advisor to GSK, Janssen and Pfizer in relation to work involving vaccines and antiviral compounds that may be effective against RSV and influenza and from the ERS for production of educational materials, he is the recipient of grants from the EU, the UK MRC and NIHR and the Wellcome Trust, he is past president and trustee of the British Society for Immunology and he is unpaid vice-chair of NERVTAG (New and Emerging Respiratory Viruses Threats Advisory Group at the UK Department of Health); MDdJ's institution received fees for his work on the scientific advisory board at Roche and Cidara pharmaceuticals, and on IDMCs for influenza antiviral trials from Janssen Pharmaceuticals, Vertex and GSK; the other authors have nothing to disclose.

Patient consent for publication Not required.

Ethics approval The study was approved by London - City \& East Research Ethics Committee (reference number 16/L0/0163) and the responsible ethics committees at all sites.

Provenance and peer review Not commissioned; externally peer reviewed.

Data availability statement The datasets generated and analysed for this report are available from the corresponding author upon reasonable request.

Supplemental material This content has been supplied by the author(s). It has not been vetted by BMJ Publishing Group Limited (BMJ) and may not have been peer-reviewed. Any opinions or recommendations discussed are solely those of the author(s) and are not endorsed by BMJ. BMJ disclaims all liability and responsibility arising from any reliance placed on the content. Where the content includes any translated material, BMJ does not warrant the accuracy and reliability of the translations (including but not limited to local regulations, clinical guidelines, terminology, drug names and drug dosages), and is not responsible for any error and/or omissions arising from translation and adaptation or otherwise.

Open access This is an open access article distributed in accordance with the Creative Commons Attribution Non Commercial (CC BY-NC 4.0) license, which permits others to distribute, remix, adapt, build upon this work non-commercially, and license their derivative works on different terms, provided the original work is properly cited, appropriate credit is given, any changes made indicated, and the use is non-commercial. See: http://creativecommons.org/licenses/by-nc/4.0/.

ORCID iDs

Malte Kohns Vasconcelos http://orcid.org/0000-0002-6207-9442

Jessica Jarvis http://orcid.org/0000-0002-8591-5378

\section{REFERENCES}

1 GBD 2015 Child Mortality Collaborators. Global, regional, National, and selected subnational levels of stillbirths, neonatal, infant, and under-5 mortality, 1980-2015: a systematic analysis for the global burden of disease study 2015. Lancet 2016;388:1725-74.

2 Beletew B, Bimerew M, Mengesha A, et al. Prevalence of pneumonia and its associated factors among under-five children in East Africa: a systematic review and meta-analysis. BMC Pediatr 2020;20:254.

3 Nair H, Simões EA, Rudan I, et al. Global and regional burden of hospital admissions for severe acute lower respiratory infections in young children in 2010: a systematic analysis. Lancet 2013;381:1380-90.

4 McAllister DA, Liu L, Shi T, et al. Global, regional, and national estimates of pneumonia morbidity and mortality in children younger than 5 years between 2000 and 2015: a systematic analysis. Lancet Glob Health 2019;7:e47-57.

5 Jiang W, Wu M, Zhou J, et al. Etiologic spectrum and occurrence of coinfections in children hospitalized with community-acquired pneumonia. BMC Infect Dis 2017;17:787.

6 Wong-Chew RM, García-León ML, Noyola DE, et al. Respiratory viruses detected in Mexican children younger than 5 years old with community-acquired pneumonia: a national multicenter study. Int $J$ Infect Dis 2017;62:32-8.

7 Bénet T, Sánchez Picot V, Messaoudi M, et al. Microorganisms Associated With Pneumonia in Children $<5$ Years of Age in Developing and Emerging Countries: The GABRIEL Pneumonia
Multicenter, Prospective, Case-Control Study. Clin Infect Dis 2017;65:604-12.

8 Lavi E, Breuer O. The impact of prior antibiotic therapy on outcomes in children hospitalized for community-acquired pneumonia. Curr Infect Dis Rep 2016;18:3.

9 Greenberg D, Givon-Lavi N, Ben-Shimol S, et al. Impact of PCV7/ PCV13 introduction on community-acquired alveolar pneumonia in children $<5$ years. Vaccine 2015;33:4623-9.

10 Izurieta P, Bahety P, Adegbola R, et al. Public health impact of pneumococcal conjugate vaccine infant immunization programs: assessment of invasive pneumococcal disease burden and serotype distribution. Expert Rev Vaccines 2018;17:479-93.

11 Kleynhans J, Cohen C, McMorrow M, et al. Can pneumococcal meningitis surveillance be used to assess the impact of pneumococcal conjugate vaccine on total invasive pneumococcal disease? A case-study from South Africa, 2005-2016. Vaccine 2019;37:5724-30.

12 Jackson C, Hsia Y, Bielicki JA, et al. Estimating global trends in total and childhood antibiotic consumption, 2011-2015. BMJ Glob Health 2019;4:e001241.

13 Levine OS, O'Brien KL, Deloria-Knoll M, et al. The pneumonia etiology research for child health project: a 21st century childhood pneumonia etiology study. Clin Infect Dis 2012;54 Suppl 2:S93-101.

14 Higdon MM, Hammitt LL, Deloria Knoll M, et al. Should controls with respiratory symptoms be excluded from case-control studies of pneumonia etiology? reflections from the PERCH study. Clin Infect Dis 2017:64:S205-12.

15 Jain S, Williams DJ, Arnold SR, et al. Community-Acquired pneumonia requiring hospitalization among U.S. children. $N$ Engl J Med 2015;372:835-45.

16 Cebey-López M, Herberg J, Pardo-Seco J, et al. Viral co-infections in pediatric patients hospitalized with lower tract acute respiratory infections. PLoS One 2015;10:e0136526.

17 Zhang X, Chen Z, Gu W, et al. Viral and bacterial co-infection in hospitalised children with refractory Mycoplasma pneumoniae pneumonia. Epidemiol Infect 2018;146:1384-8.

18 Hoffmann J, Machado D, Terrier O, et al. Viral and bacterial coinfection in severe pneumonia triggers innate immune responses and specifically enhances IP-10: a translational study. Sci Rep 2016:6:38532.

19 Brand HK, de Groot R, Galama JMD, et al. Infection with multiple viruses is not associated with increased disease severity in children with bronchiolitis. Pediatr Pulmonol 2012;47:393-400.

20 Asner SA, Rose W, Petrich A, et al. Is virus coinfection a predictor of severity in children with viral respiratory infections? Clin Microbiol Infect 2015;21:264.e1-264.e6.

21 Cebey-López M, Herberg J, Pardo-Seco J, et al. Does viral coinfection influence the severity of acute respiratory infection in children? PLoS One 2016;11:e0152481.

22 Bogaert D, De Groot R, Hermans PWM. Streptococcus pneumoniae colonisation: the key to pneumococcal disease. Lancet Infect Dis 2004;4:144-54.

23 Pneumonia Etiology Research for Child Health (PERCH) Study Group. Causes of severe pneumonia requiring hospital admission in children without HIV infection from Africa and Asia: the PERCH multi-country case-control study. Lancet 2019;394:757-79.

$24 \mathrm{Li}$ Y, Reeves RM, Wang X, et al. Global patterns in monthly activity of influenza virus, respiratory syncytial virus, parainfluenza virus, and metapneumovirus: a systematic analysis. Lancet Glob Health 2019;7:e1031-45.

25 Hammitt LL, Feikin DR, Scott JAG, et al. Addressing the analytic challenges of cross-sectional pediatric pneumonia etiology data. Clin Infect Dis 2017;64:S197-204.

26 Dunne EM, Smith-Vaughan HC, Robins-Browne RM, et al. Nasopharyngeal microbial interactions in the era of pneumococcal conjugate vaccination. Vaccine 2013;31:2333-42.

27 Skevaki CL, Tsialta P, Trochoutsou Al, et al. Associations between viral and bacterial potential pathogens in the nasopharynx of children with and without respiratory symptoms. Pediatr Infect Dis J 2015;34:1296-301.

28 Dierig A, Hirsch HH, Decker M-L, et al. Mycoplasma pneumoniae detection in children with respiratory tract infections and influence on management - a retrospective cohort study in Switzerland. Acta Paediatr 2020;109:375-80.

29 Jacups SP. The continuing role of Haemophilus influenzae type B carriage surveillance as a mechanism for early detection of invasive disease activity. Hum Vaccin 2011;7:1254-60.

30 Kohns Vasconcelos M, Renk H, Popielska J, et al. SARS-CoV-2 testing and infection control strategies in European paediatric emergency departments during the first wave of the pandemic. Eur $J$ Pediatr 2021;180:1-7. 
31 Vasconcelos MK, Epalza C, Renk H, et al. Harmonisation preserves research resources. Lancet Infect Dis 2021;21:e71.

32 Azadeh N, Sakata KK, Saeed A, et al. Comparison of respiratory pathogen detection in upper versus lower respiratory tract samples using the BioFire FilmArray respiratory panel in the immunocompromised host. Can Respir J 2018;2018:2685723:1-6.

33 Boonyaratanakornkit J, Vivek $\mathrm{M}$, Xie H, et al. Predictive value of respiratory viral detection in the upper respiratory tract for infection of the lower respiratory tract with hematopoietic stem cell transplantation. J Infect Dis 2020;221:379-88.

34 Loens K, Van Heirstraeten L, Malhotra-Kumar S, et al. Optimal sampling sites and methods for detection of pathogens possibly causing community-acquired lower respiratory tract infections. $J$ Clin Microbiol 2009;47:21-31.
35 Nascimento-Carvalho CM. Community-Acquired pneumonia among children: the latest evidence for an updated management. $J$ Pediatr 2020:96 Suppl 1:29-38.

36 Schuh S, Babl FE, Dalziel SR, et al. Practice variation in acute bronchiolitis: a pediatric emergency research networks study. Pediatrics 2017; 140:e20170842.

37 Tannous R, Haddad RN, Torbey P-H. Management of communityacquired pneumonia in pediatrics: adherence to clinical guidelines. Front Pediatr 2020;8:302.

38 Donà $\mathrm{D}$, Barbieri $\mathrm{E}$, Daverio $\mathrm{M}$, et al. Implementation and impact of pediatric antimicrobial stewardship programs: a systematic scoping review. Antimicrob Resist Infect Control 2020;9:3.

39 Feudtner C, Feinstein JA, Zhong W, et al. Pediatric complex chronic conditions classification system version 2: updated for ICD-10 and complex medical technology dependence and transplantation. BMC Pediatr 2014;14:199. 